A TRAVELLER'S DIGITAL IDENTITY:

\title{
AN ANALYSIS OF CURRENT MOBILE TRAVEL APPS AND TOURIST BEHAVIOURS FOR BETTER DIGITAL DISCOVERY IN URBAN ENVIRONMENTS
}

\author{
by
}

\author{
Rebecka A. Calderwood \\ Bachelor of Journalism, Ryerson University, 2015
}

\begin{abstract}
A Major Research Paper
presented to Ryerson University

in partial fulfillment of the requirements for the degree of Master of Digital Media in the Program of Digital Media
\end{abstract}

Toronto, Ontario, Canada, 2017

(C) Rebecka A. Calderwood, 2017 


\section{Author's Declaration}

I hereby declare that I am the sole author of this Major Research Project (MRP). This is a true copy of the MRP, including any required final revisions.

I authorize Ryerson University to lend this MRP to other institutions or individuals for the purpose of scholarly research.

I further authorize Ryerson University to reproduce this MRP by photocopying or by other means, in total or in part, at the request of other institutions or individuals for the purpose of scholarly research.

I understand that my MRP may be made electronically available to the public.

Rebecka A. Calderwood 


\begin{abstract}
A TRAVELLER'S DIGITAL IDENTITY:

AN ANALYSIS OF CURRENT MOBILE TRAVEL APPS AND TOURIST BEHAVIOURS FOR BETTER DIGITAL DISCOVERY IN URBAN ENVIRONMENTS
\end{abstract}

\author{
Master of Digital Media, 2017 \\ Rebecka A. Calderwood \\ Master of Digital Media, Ryerson University
}

The purpose of this research is to improve an understanding of travellers as users of mobile travel applications (apps). Research was conducted on travel motives, mapping and navigationrelated technology, as well as mobile travel app attributes to find the best design and performance solutions for user engagement. Secondary research and a competitive analysis of current mobile travel apps was performed to rate the effectiveness of app interfaces. Using these findings as a guide, it proposes an interactive self-guided travel app under the title DROP/PIN. DROP/PIN allows travellers to explore urban environments in real-time through personalized interests, big data, instant messaging and navigational technology. Through this implementation, a prototype of the app was created. DROP/PIN aims to foster a traveller's digital identity through constant personalization and data recognition, social interactions by profile compatibility, and a common interest in global exploration.

Keywords: Urban Navigation, Mobile Travel Apps, Personalization, User Experience, App Design \& Performance, User Engagement, Tourist Behaviour 


\section{Acknowledgements}

This major research paper would not have been possible without the feedback, patience and guidance of my academic supervisor, Dr. Alex Ferworn of Ryerson University. Thank you to Michael Carter, MDM Director of Industry Relations, for being accommodating throughout the busy and intensive year of the MDM program. Additionally, I would like to thank Sonya Taccone, MDM program administrator, for showing me my own compassion and reminding me of the strength and resilience in us all.

I would like to acknowledge a close friend and the one behind the prototype of DROP/PIN, Michael E. Tretiak. He has always believed in my ideas and intellect, been there to pick me up on my worst days, and taught me I am worthy of more than I give myself credit.

Lastly, I am very grateful for all of my extraordinarily talented peers and lifelong friends I've made in the MDM 4.0 cohort whom have undoubtedly taught me to see business, design and technology in a different light, but also to see the endless possibilities of our future through humanity, innovation, and a positive attitude. The past year has been a whirlwind of emotions and adventures that has helped me grow as an individual just as much as an industry professional. Thank you for being an integral part of my journey. 


\section{Table of Contents}

Author's Declaration $\quad$ ii

Abstract $\quad$ iii

Acknowledgements iv

Table of Contents $\quad$ v

List of Figures $\quad$ vi

$\begin{array}{ll}\text { 1. Introduction } & 1\end{array}$

2. Literature Review $\quad \mathbf{4}$

2.1.Spatial navigation and digital mapping 4

2.2. Shaping travellers' identity 5

2.3.How digital personalization works 6

2.4.Photo sharing among tourists 9

2.5.The importance of user engagement 12

3. Methodology 14

3.1.Research model 15

3.2.Analyzing app attributes: design 17

3.3. Analyzing app attributes: performance $\quad 19$

3.4.Competitor analysis based on proposed app attributes 20

4. Evaluation \& Findings 33

4.1.Literature review findings 33

4.2. Competitor analysis findings 34

5. Conclusions $\quad 39$

5.1.DROP/PIN purpose 41

5.1.1. Design interface 42

5.1.2. Technology \& permissions 44

5.2. Limitations 45

5.3. Future work 47

$\begin{array}{ll}\text { References } & 48\end{array}$

$\begin{array}{ll}\text { Glossary } & 51\end{array}$ 


\section{List of Figures}

Figure 1. Architecture of ADaPT Personalization System

Figure 2. S-O-R Relationship Model with App Attributes for User Engagement

Figure 3. Competitor App Design

Figure 4. Competitor App Performance

27

Figure 5. User Satisfaction of Mobile Travel Apps Based on Interface Approach 


\section{Introduction}

This research addresses a gap in mobile travel apps in regard to user personalization and social interaction to achieve high user engagement when exploring new cities. Through secondary research and a competitive analysis of current mobile travel apps, an ideal mobile travel app is explained and prototyped to create a traveller's digital identity. The app, DROP/PIN, is a way for travellers to find sights and places within a destination that cater to their interests while continuously building a travel profile for their future travel destinations. This research discusses personalization, current navigational technology, user engagement through app design and performance, and social interactions for travel app development. A recent study shows that 85 per cent of travellers use a mobile device to book travel activities (Opera Mediaworks, 2016). Knowing this, it was important to address the current market of popular mobile apps used for travel (Yelp, TripAdvisor, Sidekix, Spotted by Locals, City Guides by Facebook, Google Trips, Guides by Lonely Planet, and Google Maps) through a competitive analysis. This paper supports a viable solution to mobile self-guided discovery in urban environments as a means to aggregate, shape and guide the user to a personalized experience while tandemly providing more precise development of DROP/PIN's prototype.

DROP/PIN would be accessible to anyone with a smartphone, allowing travellers to experience all urban destinations however they see fit. Since it is common for many travellers to be without a service provider out of their native country, the app would need to be downloaded when connected to Wi-Fi prior to use. However, once downloaded the user can allow or deny access to the app in order receive the user's preferences based on personal data. With or without denying access to personal data, the user must complete a travel profile aimed for the app to 
understand the traveller's goals; therefore, giving the most personalized travel experience for the user.

This research is inspired and supplemented by trends in the travel industry in relation to traveller motives and movement patterns, as well as existing resources for exploring and navigation techniques for wayfinding. Currently, the gap lies in understanding the traveller as a smartphone user. There are many mobile travel apps that provide guidance and aid when choosing the best excursions, wayfinding and navigation options, as well as promoting exploration. However, there isn't one that modifies sights and events within cities to cater to the user's past experiences and current travel goals, while simultaneously connecting the users to one another travellers. The goal of DROP/PIN isn't just to create a personal travel profile, but to create a digital community of travellers who have one common goal of discovering new places around the world.

This paper applies a research model for mobile travel app user engagement through design and performance app attributes. With the research model presented, it analyzes existing travel apps to grasp the user within a traveller context. The contributions of this paper include knowledge of navigation and mapping destinations and its use of big data to present a new method of personalized travel planning and exploration in urban environments. I claim that analyzing travellers' habits and design interface attributes of mobile travel app competitors will increase an understanding of a traveller's digital identity, allowing for implementation of a travel app through personalization, navigational technology, and social interactions.

The following research has been organized as follows: firstly, to analyze a traveller's identity through habits, movement patterns, and motives as seen in a digital and technological 
realm. Secondly, to inspect and compare how app design and performance in mobile travel apps affects user engagement. And lastly, to use the previous research and analysis to implement a self-guided travel app built for high user engagement through personalization and social interactions. 


\section{Literature Review}

\subsection{Spatial navigation and digital mapping}

Navigation plays an integral part in exploring a new city; It is what people must do when presented with a new landscape. Beyond the traditional map, navigation has made its way into the pockets of travellers through the technology and accessibility of our handheld smartphones. Mapping and navigation services provide users with a multitude of ideas for where to go, why to go there, and how to effectively map your route: "These services arrange space in order to facilitate meaningful and productive navigation (Rice, 2008)." By doing so, information on the Web, used through mobile application services, can show a user "new ways space affects inventive practices" (Rice, 2008). Through constructing databases Rice recognizes how technology and mapping are complementary, rhetorical systems (2008). The "rhetoric of the Network" that Rice speaks to is proven through the influx of databases that technology has allowed for its users. "Databases might provide insight into how we arrange and invent within a variety of spaces, from the physical to the conceptual (Rice, 2008).” The challenge with mobile apps for navigating and mapping destinations to explore lies with crowd-sourced information and a continuous network on which to increase and develop databases. When comparing print-based maps to database mapping service, Rice acknowledges its challenges, which heavily involve mass amounts of information to create, navigate and position. This results in even more ways for the user, or traveller, to get from one destination to another. It is with this information that building mobile travel apps becomes more difficult for the developer. The amount of data to leave in or leave out could result in less accurate personalization for the user. Rice puts an emphasis on Google Maps as convenient and novel; however, unsuccessful in constructing a personalized network. "Google Maps is not 'wrong,' but it does ask that I consider networks, 
space, and navigation further so that personalized data is also included... the personalization of data extends and complicates traditional applications of rhetorical tools like memory so that other forces and spaces - like sensations, citations, quirky data, and so on - are included as well” (Rice, 2008). In order for a travel app to encompass discovery and exploratory states for a user it must get to know the personality of the user as a traveller.

\subsection{Shaping travellers' identity}

Furthermore, there is an identity of a place as it pertains to the traveller and travellers of the past, Rice explains. With each new traveller to a destination, there becomes a new identity of the destination, along with that of the traveller. However, this identity, "is a variable that depends on how [someone] access[es] [their] databases" (Rice, 2008). Having access to database-driven information within a new urban experience results in an ever-changing identity. Lynch's (1960) research describes traveller identity best:

"Nothing is experienced by itself, but always in relation to its surroundings, the sequences of events leading up to it, the memory of past experiences... every citizen has had long associations with some part of his city, and his image is soaked in memories and meanings."

While Lynch most commonly speaks to architecture and shaping cities, he helps to define how a city can have effects on each of its travellers and dwellers within a more personal context. Lynch's understanding of individualized views of a destination or city can lead to the notion that having a personal tour of any urban environment can aid a traveller to have a more positive experience with lasting perceptions and meaning. Rice agrees and states that: "through the sharing of data, these engagements cause me to form a meaning. [Engagements are] a network 
directing understanding and invention of space" (2008). Concluding this analysis of spatial navigation with personal experiences proposes that there will never be a single or correct way to navigate, "rather, there is a consistent use and organization of definite sensory cues from the external environment" (Lynch, 2008). From this analysis, DROP/PIN's algorithm to navigate urban environments must heavily depend on the user's unique personalized interests, whereby sights or destinations within a city can be consistently updated to match the individual needs of the traveller at any given time. This allows for constant control of personalization. Although it brings about more data to DROP/PIN's users, resulting in potential margin of error, this personal database within the app becomes a trusted source of memory for destination experiences.

\subsection{How digital personalization works}

It's one thing to explain that personalization increases a traveller's digital identity, but the systems behind personalization further allows a grasp of how its digitally possible. The Automatic Data Personalization and Tailoring System provides insight through demonstration into the systems that make personalization possible (Miele et al., 2014). People are surrounded by data-oriented applications, and smartphones reinforce this trend, highlighting the example of how quickly it is to use TripAdvisor to find restaurants (Miele et al., 2014). Two risk factors in this data-oriented application are explained. Firstly, there is an overwhelming amount of data resulting from queries being too vague or the large amount of search results (Miele et al., 2014). The second results in access to Internet while in a foreign place. Internet is not always guaranteed in a country, roaming costs are high, and data is limited and dependent on the data plan of the individual smartphone user. Miele et al. call this lack of disk space and bandwidth "information starvation" (2014). The solution, Miele et al. suggests, is tailoring the database content to the user also known as personalization (2014). ADaPT: Automatic Data 
Personalization and Tailoring is a system that allows the collection of users' choices (of querying and other activity) in various possible contexts. It learns from these choices in order to be able to provide each user with the most relevant portion of information when the same context arises (2014). Personalization, herein, refers to "the tailoring of the database according to the current context and to the preferences (implicitly) expressed by the user by performing data-access in that specific context" (2014). A graphical user interface (GUI), which is an interface that allows users to interact with electronic devices through visual interactions, makes this possible. Fig. 1 shows a diagram of this system at work.

\section{Figure 1. Architecture of ADaPT Personalization System}

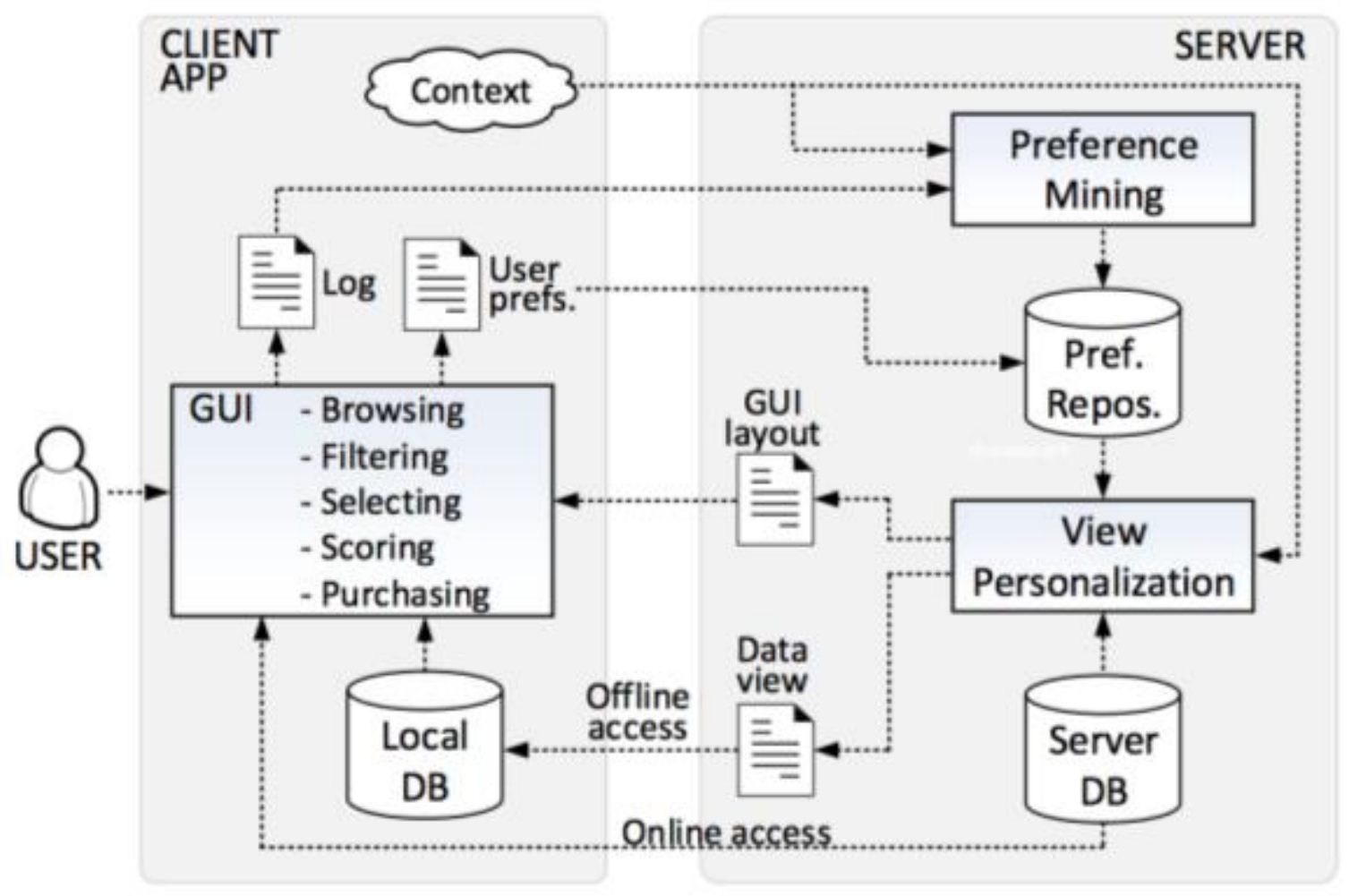

The demo Miele et al. use shows the interaction between the client application and the server. It works as follows: personalized data is provided through a GUI running on a 
smartphone. This is the client application, also known as the user side of the system. The server application is the database that does the personalization for the user. The user views the data through an interface (which shows significance of this research and will be analyzed in the methodology). This exchange can work without an Internet connection while still logging user activity, and consequently, logging preferences of the user. Miele et al. explain what the client application provides for the user. Note that the example has been changed to reflect research based on travel preferences:

- Browsing the items contained in a table (e.g. lists of destinations and sights within a city);

- Filtering a table according to a specified criterion (e.g. filtering destinations and sights according to category);

- $\quad$ Selecting a specific item to see its details (e.g. get the details of each destination or sight);

- Scoring a certain item, like a destination, to manually specify a preference on that tuple (e.g. rating and reviewing);

- Purchasing the item (e.g. tickets for an attraction).

As more data is collected from the user through this system, preferences are updated, which further improves the personalization for the user and his or her experience. The conclusion of this research shows a system that allows "a user to access a personalized view on the database, and a server-side software able to extract the user's contextual preferences from log data and to use them to realize the personalization" (Miele et al., 2014). This research provides a basis for the personalization system that will be used in DROP/PIN app development to allow a consistent aggregation of interests and preferences to help the user form a traveller's digital identity. 


\subsection{Photo sharing among tourists}

The importance and prevalence of social media and photo sharing behaviour in the tourism industry becomes more evident for understanding traveller habits in Leung et al.'s research (2017). A study conducted by Leung et al. extracts and processes geotagged photos "uploaded by inbound tourists on Fickr.com to study tourists' photo sharing and visiting pattern during their visits to Hong Kong temples” (2017). Specifically, it identifies popular attraction spots in Hong Kong and associates it with tourists' visit patterns. By analyzing this research it's possible to extract potential attractions in terms of tourists' interests and their travel pattern. The article highlights the digital trend of geotagging, meaning "the process of attaching geographical identification metadata into multimedia files such as images and videos to identify tourists behaviour and movement" (Zheng et al. 2012). Geotagging is common in social media platforms, especially Snapchat and Instagram. It allows users to connect multimedia to a specific location, and depending on the users' privacy settings, also allows the users to share and extract with each other. Technology has aided in understanding tourists' behaviour; "Geographic Information System (GIS) and Global Positioning System (GPS) has made it possible for researchers to explore tourist's movement patterns" (Lau and Mckercher, 2006). Lau and McKercher recognize tourists' movement patterns within a destination based on GIS. The find that "at the local level, tourist travel within a single destination from attraction to attraction, or shifting from activity to activity" (2006). Therefore, there are two ways tourists move: inter-destination and intradestination. Inter-destinations are the movements from tourist-generating regions to one or more destinations, while intra-destinations are the directions within a destination at which the tourist moves (Lau, McKercher, 2006). This research focuses on inter-destination movements, as the users would use the DROP/PIN to find the next appealing destination within a place. Suggested 
by Lau and McKercher, tourist movement patterns may pertain, not only to space, but may also be reflected by differences in trip profile, personal motives, physical configurations of destinations, prior visitation and time. (2006). These factors affecting tourist movement patterns are considered heavily when designing the DROP/PIN application interface and interactivity for its user. Most importantly, these factors of tourists' movements will be used to maximize the travel experience for the amount of time the traveller has in each location. Though movement patterns play a part in tourists' travels, there is a psychological reason for where and how people travel.

The perception of the "environmental bubble," which was first introduced by Erik Cohen in 1972 describes 'psychological comfort' from mass tourists in order to interact in another place the same way as in your own habitat. Cohen classified travellers based on this perception. The classifications are: organized mass tourist, individual mass tourist, explorer and drifter (1972). Organized mass tourists generally remain in this figurative bubble when they are in an unknown destination, resulting in routine movement patterns, while explorers tend to jump at opportunity to explore. DROP/PIN serves as a means to disrupt routine movement patterns while also allowing travellers to psychologically feel in control of their own itinerary. The application interface and GPS guide allows travellers to have personal control over. Itineraries for explorertype travellers are planned based on discovery aspirations of the traveller. Explorer type travellers participate in activities that aren't entirely familiar (Lau and McKercher, 2007). This is the classification group that DROP/PIN will cater towards.

Social media plays a big role in building and setting up opportunities for user engagement as a means to develop a vibrant online community with users who are active travellers. Interactions made through geotagging and photo sharing provide insights on tourists' movement 
patterns, which can additionally provide an understanding of social media behaviour amongst users. Konijn et el. State that: "Visualization of tourism experiences through photographs is an important part of our increasingly digitized society. Intertwined with tourist photography is the social sharing of photos" (2016). This digital exchange of user-generated content must be factored into mobile travel app user engagement as travellers tend to practice photography in order to share their experiences with others. While Konijn et al. explain many hypotheses of tourist photography behaviour - from recreations of photographs seen in advertisements or postcards - "photographing may result not only in photographs but also in relationship development between the people involved" (2016). The study adopts the framework of seeing tourists as both passive reproducers of images and active self-expressive amateur. It also highlights photo-sharing behaviour from tourists, suggesting that digital cameras and smartphones encourage spontaneous and frequent photographs (Konijn et al., 2016).

The most recent addition in the social media realm is SnapChat - the app that allows users to "snap" photos and videos that self-destruct in up to 10 seconds or until the receiving user taps to exit the snap. (This length depends on the time frame the sending user sets for each snap.) SnapChat has feature called Snap Map, which gives users the ability to track and view where their friends are at any given moment on a map of the world. This is only possible if the user allows permission for the app to track and show their location. Snap Map also allows the user to see snaps (short videos and photos that only last 24 hours) of happenings and major events from around the world. In a recent article from Refinery29 Jack Brody, a product designer at SnapChat is quoted to saying, “This map isn't about where am I. It's about where are my friends and what are they up to? It's not about figuring out how to get to your destination, but about discovering where you want to go" (2017). Furthering this notion, Brody states in the article that, 
“one of the habits we've seen with our users is that they'll take a snap where they are, put on a geofilter, and post it to their story (the spot a user posts for all his or her friends to see) ..."

(2017). This new kind of photo sharing, combined with geolocation, is what users are looking for in an app used for digital social interactions. Since SnapChat is currently used as a social media tool amongst friends, there still might be room for a mobile travel app, such as DROP/PIN, to hit the market.

\subsection{The importance of user engagement}

As social media increasingly becomes a tool used to discover world events, local happenings and nearby activities, the physical properties connected to this behaviour must be further explored. In Design and performance attributes driving mobile travel application engagement, J. Fang et al. iterate how companies are taking advantage of mobile travel apps to retain "a committed, engaged user base and boost sales" (2017). This study helps to explain what factors influence a user's engagement while using mobile travel apps. It also highlights the need for clarifying the definition and context of engagement behaviour, adoption, and continuous usage in the scenario. Engagement behaviour refers to "users' continued interaction with a mobile app after adoption" (J. Fang et al., 2017). Adoption comes in two forms: technology and app. Technology adoption is the starting point of engagement, while app adoption is when the app has been selected to be used (J. Fang et al., 2017). Once the app has been adopted, continuous usage comes into play, which refers to the continual use of a product over time after its initial adoption period (J. Fang et al., 2017). However, engagement is the users' continued interaction with a product, meaning the users' experience with the app - in this case DROP/PIN. DROP/PIN's main mission is to support continued interaction amongst its users. "It is more important for companies to cultivate users' engagement behaviour than to focus simply 
on users' continuance usage so that the company can build and maintain a vibrant online community, develop a solid customer relationship, and create a sustainable long-term competitive advantage" (J. Fang et al., 2017). One of main principles of DROP/PIN lies in understanding the user. This is especially important because the user is getting to know themselves and their own travel identity through DROP/PIN. Social interactions within the app make it possible for users to stay engaged; therefore, allowing DROP/PIN to cultivate users' engagement. Its purpose is to build a community of digital travellers. 


\section{Methodology}

At the onset of this research paper a literature review was conducted to discover aspects of a traveller's digital identity. Starting with the most basic navigational tool: a map. With digital maps, navigational databases and mapping resources have changed the way people discover new places and things to do. This research helped to define who was using the map, in this case the user became defined as the traveller. With databases continuously growing, the traveller (as a user) has copious amounts of information at all times. For the user, this issue can often lead to vague queries or search results for navigation. Personalization of discovery databases identified the need for the user to have an effective travel experience. Though navigation is not, and cannot have any set arranged pattern (Lynch, 2008) in a digital mapping era, personalization would allow the traveller to receive just the right amount of the guidance when using a mobile travel app. After exploring personalization for a traveller, the need to define it on a physical level became clear. This lead to research in Automatic Data Personalization and Tailoring, also known as $\mathrm{ADaPT}$. This is a system that collects user data through queries in a specific context (Miele et al., 2004). Still, more information about how the user moves when touring new locations was required. Tourists movement patterns were analyzed. The results formed the basis for the questions DROP/PIN would ask the user in order to personalize the individual's self-guided tour. Next, design research for DROP/PIN was required. This is where the research model was used to analyze the current selection of travel apps used for travel discovery. The goal of this analysis is to grasp how user engagement would affect the development of DROP/PIN's design interface. Continued research in engagement through social avenues came next. Community engagement online would seek to gain competitive advantage; therefore, building DROP/PIN with social interactions present in the app would be needed. Social interactions with travel are often based 
on photography and sharing of such over social media. These interactions, as seen through research, have included geotagging of photos while sharing them as a contributor to user engagement. After this detailed process of understanding a traveller's digital identity, DROP/PIN began to have a basis for development, as you will find in the conclusion. First, here is a closer look at the competitive analysis of current travel apps.

\subsection{Research model}

In order to effectively comprehend if DROP/PIN could fit into the mobile travel application, its competitors had to be thoroughly analyzed. This research will focus on the user's experience, specifically their engagement behaviour through design and performance. This competitive analysis of travel applications relies heavily on the research from the study, Design and performance attributes driving mobile travel application engagement (2017). It uses the SO-R (Stimulus-Organism-Response) Relationship about human behaviour theory to understand user engagement with a travel app. It recognizes two domains: app design and app performance (J. Fang et al., 2017). For this research, which aims to be useful in a technology industry, those attributes will refer to user interface and user experience design. DROP/PIN will use the practical implications based on J. Fang et. al's study to optimize customer engagement for its users. 


\section{Figure. 2: S-O-R Relationship Model with App Attributes for User Engagement}

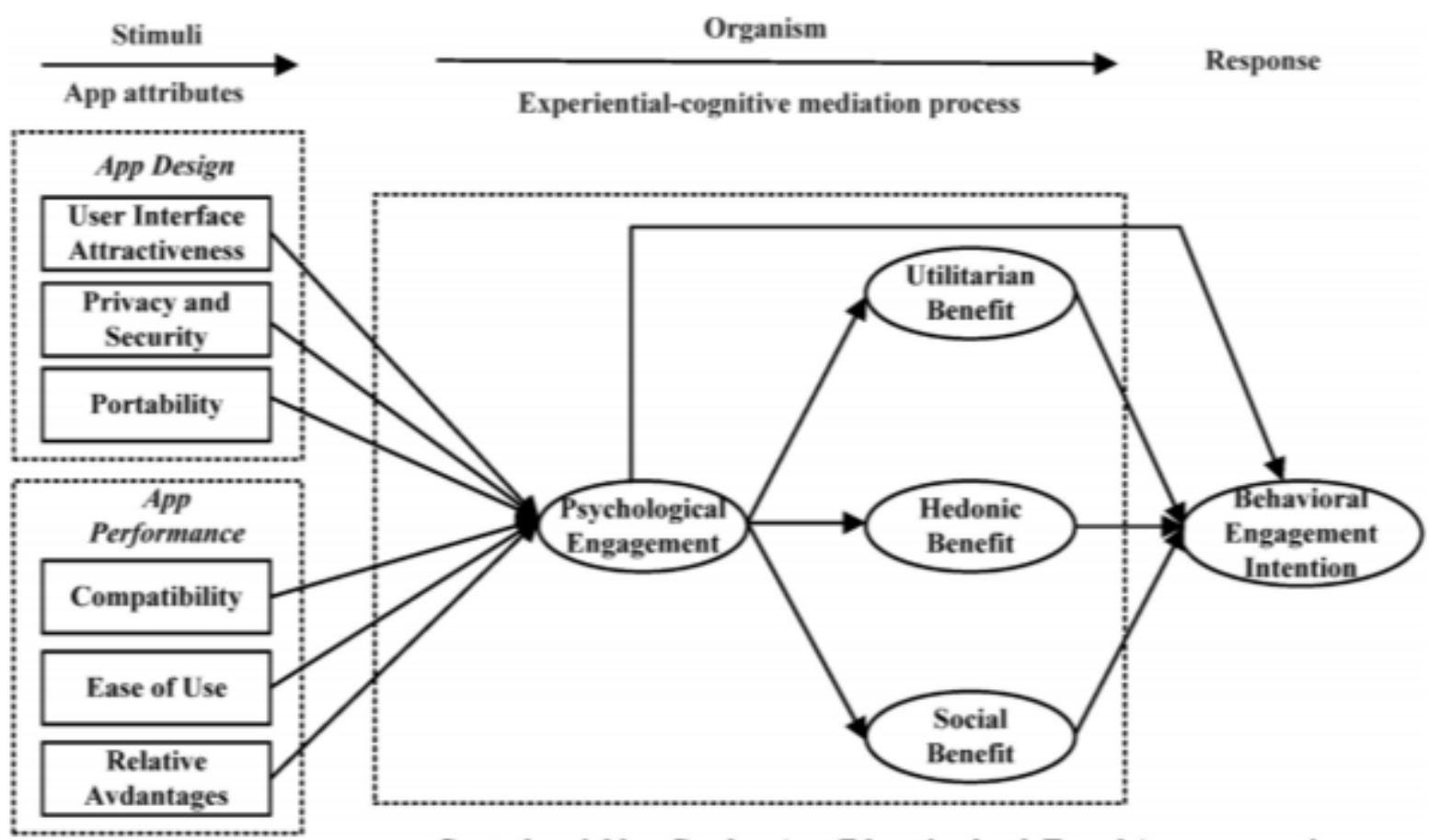

Control variables: Gender, Age, Education level, Travel App use experience

The study's research features flexibility, attractiveness, and the ease of use as factors of an individual's psychological engagement, while referring to game customization as a means for high customer experience, thereby resulting in higher customer behavioural engagement. With these factors in mind, the study then puts the S-O-R model to use with its research model found in Fig. 1. The S-O-R model begins with (S)timuli. This refers to the app attributes that ultimately attract the user. Parboteeah et al. (2009) speaks to website characteristics on the consumer's urge to buy impulsively, and as J. Fang et al. (2017) reiterates in the study, website characteristics are part of an environmental stimuli for the user. Parboteeah et al. (2009) and J. Fang et al. (2017) say that security, download delays, ease of navigation, information fit-to-task (how information presented is accurate and appropriate to a goal or task), and visual appeal (relating to fonts, 
graphics and overall look) are all part of stimuli that app developers must take into account if successful user engagement is to be fulfilled. This stimulus is what brings the user to the (O)rganism, meaning the experiential-cognitive mediation process or what the user perceives to believe makes the app effective for him or her. Soon thereafter, the user has a (R)esponse: the behavioural engagement intention. It is at this final stage that the user decides whether to, or the extent of which to, engage in the mobile app. This research study used will be the most beneficial for DROP/PIN to follow as it relies on a closer look at structural quality (design) and software functional quality (performance) (J. Fang et al., 2017). These app attributes are seen as environmental stimuli to evoke app users'. This creates experiences, also known as psychological engagement, and benefits (utilitarian, hedonic, and social). These experiences and benefits are what defines user engagement (J. Fang et al., 2017). Additionally, the approachavoidance behaviours of technology that the study suggests are as follows:

1. Product appearance (visual appeal and prototypically),

2. Product performance (usefulness, ease of use and innovativeness of technology), and

3. Product communicative power (self-expression) (J. Fang et al., 2017).

In order to convey product communicative power, the product must have a reputation. While it's important to keep this in mind for DROP/PIN's future work and implementation, this study did not include it in its research.

\subsection{Analyzing app attributes: design}

As previously mentioned, UI attractiveness, privacy and security, and portability will be considered in the design section of app attributes. In order to analyze these attributes, they must first be defined. UI attractiveness refers to “one's perception of aesthetic attractiveness of a 
mobile travel app derived from UI design factors such as colour schemes, spatial layout details and shape selection" (J. Fang et al., 2017). In other research, app design is the first and foremost influencer for a user. This means that if the app design is attractive, the user will be engaged and increase system use (Peters et al., 2013).

Privacy and security is the "perceived ability of individuals to control when, how, and to what extent their personal data in mobile apps are accessed, modified or disclosed" (J. Fang et al., 2017). As users become more and more skeptical about where their information is going, guidelines and security permissions in the app are increasingly more important. They directly impact the user's engagement with the app and the user's opinion of the creator company. This is when personalization and big data can intersect. Without privacy and security permissions from the user, the user is not able to make app-specialized personalizations in order to use DROP/PIN effectively. If neither big data nor the personalization sign up survey are used, the user will not receive a high engagement within DROP/PIN, as this is the basis for which it can successfully operate for the user. By using Peters et al.'s research model, DROP/PIN would require good privacy and security protection design, thus allowing the user to demonstrate their essential interest in the app. This allows the user to "devote their effort and energy to interacting with the app" and "be deeply absorbed in the highly enthusiastic about the interaction" (2017).

Portability is the final attribute for analyzing app design. This is the ability to be executed on different mobile operating systems (OS), such as Android, iOS, and Windows Mobile (J. Fang et al., 2017). Since a range of smartphone users have different mobile devices, the app would be cross-platform to accommodate a wider variety of users. This is both beneficial for the app company and for travellers who want self-guided city tours delivered through their mobile phone. In addition, should a user have to switch from one OS to another, this could result in a 
user's perceived cost of learning (time and effort for the user to understand and learn to how to use a product/service) and personal relationship (a user's affective losses associated with breaking ties with other app users with whom the user has interacted) (J. Fang et al., 201). Again, DROP/PIN will ensure these components of app design furthers the user's engagement and sense of identity towards the app.

\subsection{Analyzing app attributes: performance}

App performance attributes refers to compatibility, ease of use, and relative advantages. Compatibility in app attribute context reflects the users' perception of how the app fits travel needs and preferences (J. Fang et al., 2017). In other words, it is the compatibility of the user's needs to what purpose the app serves. J. Fang et al. concludes that higher levels of compatibility are associated with higher levels of a users' psychological engagement (2017). Knowing this, compatibility for DROP/PIN would mean that the user's purpose for engaging in the app would be to receive a personalized self-guided tour through his or her smartphone.

Ease of use is perhaps the most simplistic to understand, meaning the degree to which the user can understand and operate tasks within the app. Huang and Hsieh hypothesis that complexity of a product (ease of use) is highly incumbent on the user's satisfaction (2012). This complexity tends to suggest unclear understanding and vagueness, resulting in lower user engagement, or worse, switching apps altogether. If a travel app is easy to use the user is more likely to stay engaged and loyal to the app.

Relative advantage is most difficult to overcome for a new app. It describes the "extent to which users regard a specific travel app to be superior to other existing travel apps" (J. Fang et al., 2017). However, in the startup world, relative advantage is the driving factor for every new 
company; J. Fang et al. suspect it is the innovativeness of a product or service (2017). To measure relative advantage, Huang \& Hsieh say the product must be something that makes the consumer incur tangible and intangible benefits of functionality and degree of personalization (2012). In order for DROP/PIN to succeed as a multi-dimensional product, intangible elements will come in the form of a personalized survey to customize trips per urban destination. Tangible benefits would include the rewards you receive from experiencing the personalized trip. This could be in the form of the DROP/PIN personalization algorithm by finding a local restaurant or café in between designated stops within custom trip itineraries. It could also be a specific location within a destination that may remind you to pick up souvenirs for loved ones back home. In this instance the multi-dimensional element of relative advantage works to increase the exploring experiencing.

\subsection{Competitor analysis based on proposed app attributes}

Competitors have been selected based on the need for urban navigation and sightseeing destinations when travelling within intra-destinations (directions and places where tourists go within a destination). The list of competitors does not include travel apps used for accommodation and lodging, or transportation (as DROP/PIN is used for pedestrian wayfinding), language barriers (although language options will be available for the user), or preparation (currency, packing, etc.). This list is based on discovery purposes while travelling, meaning the goal is to find or explore a new location. Each competitor's design and performance was solely analyzed in a mobile app context. While it's common for responsive design (interface design with varying sizes used to fit multiple viewing screen sizes) to be seen across most apps, this analysis will solely focus on the mobile views. 
Based on the secondary research provided in the research model, each competitor has been given a description of each app attribute. Whether or not the competitor is effective or ineffective relies on how each attribute impacts overall user engagement. Fig. 3 describes design app attributes: user interface attractiveness, privacy and security, and portability. Fig. 4 describes performance app attributes: compatibility, ease of use, and relative advantages. The following analysis [Fig. 3 and Fig. 4] was taken from Google Play Store (for Android) and iTunes App Store (for iOS).

\section{Figure 3. Competitor App Design Attributes}

\begin{tabular}{|c|c|c|c|}
\hline & $\begin{array}{l}\text { User Interface } \\
\text { Attractiveness: } \\
\text { What is the colour } \\
\text { scheme and spatial } \\
\text { layout (basic } \\
\text { design/look)? }\end{array}$ & $\begin{array}{l}\text { Privacy \& Security: } \\
\text { What information is taken from the } \\
\text { user once they accept permissions? }\end{array}$ & $\begin{array}{l}\text { Portability: } \\
\text { What operating } \\
\text { systems are } \\
\text { available? }\end{array}$ \\
\hline Yelp & $\begin{array}{l}\text { Colour Scheme: On } \\
\text { brand - red and } \\
\text { white. } \\
\text { Spatial Layout: } \\
\text { Word heavy, though } \\
\text { relies on photo } \\
\text { galleries from } \\
\text { crowd-sourcing, } \\
\text { overuses algorithm } \\
\text { to find various types } \\
\text { of services although } \\
\text { primarily used for } \\
\text { dining and delivery } \\
\text { (food industry), too } \\
\text { many. }\end{array}$ & $\begin{array}{l}\text { Identity: find accounts on the device } \\
\text { Contacts: find accounts on the } \\
\text { device, read your contacts } \\
\text { Location: approximate location } \\
\text { (network-based), precise location } \\
\text { (GPS and network-based) } \\
\text { Phone: read call log } \\
\text { Photos/Media/Files: read the } \\
\text { contents of your USB storage, } \\
\text { modify or delete the contents of } \\
\text { your USB storage } \\
\text { Storage: read the contents of your } \\
\text { USB storage, modify or delete the } \\
\text { contents of your USB storage } \\
\text { Camera: take pictures and videos }\end{array}$ & $\begin{array}{l}\text { Available on both } \\
\text { Android and iOS: } \\
\text { - Android OS } \\
\text { varies with } \\
\text { device } \\
\text { - iOS requires } \\
\text { version } 9.0 \text { or } \\
\text { later }\end{array}$ \\
\hline
\end{tabular}




\begin{tabular}{|c|c|c|c|}
\hline & & $\begin{array}{l}\text { Microphone: record audio } \\
\text { Other: receive data from the } \\
\text { Internet, view network connections, } \\
\text { full network access, run at startup, } \\
\text { control vibration, prevent device } \\
\text { from sleeping, read Google service } \\
\text { configuration }\end{array}$ & \\
\hline TripAdvisor & $\begin{array}{l}\text { Colour Scheme: } \\
\text { Consistent with } \\
\text { logo a brand. } \\
\text { Spatial Layout: } \\
\text { Uses good amount } \\
\text { of whitespace, uses } \\
\text { good contrast } \\
\text { between photos and } \\
\text { texts, concise } \\
\text { navigation } \\
\text { throughout, focuses } \\
\text { on hotels and } \\
\text { restaurants. }\end{array}$ & $\begin{array}{l}\text { Identity: find accounts on the } \\
\text { device, add or remove accounts } \\
\text { Contacts: find accounts on the } \\
\text { device } \\
\text { Location: approximate location } \\
\text { (network-based), precise location } \\
\text { (GPS and network-based) } \\
\text { Storage: read the contents of your } \\
\text { USB storage, modify or delete the } \\
\text { contents of your USB storage } \\
\text { Camera: take pictures and videos } \\
\text { Other: receive data from the } \\
\text { Internet, view network connections, } \\
\text { create accounts and set passwords, } \\
\text { full network access, run at startup, } \\
\text { use accounts on the device, prevent } \\
\text { device from sleeping, read Google } \\
\text { service configuration }\end{array}$ & $\begin{array}{l}\text { Available on both } \\
\text { Android and iOS: } \\
\text { - Android OS } \\
\text { varies with } \\
\text { device } \\
\text { - iOS requires } \\
\text { version } 9.0 \text { or } \\
\text { later }\end{array}$ \\
\hline $\begin{array}{l}\text { Guides by } \\
\text { Lonely } \\
\text { Planet }\end{array}$ & $\begin{array}{l}\text { Colour Scheme: } \\
\text { minimalist and } \\
\text { greyscale, with blue } \\
\text { Lonely Planet logo. } \\
\text { Simplistic and clean } \\
\text { - straightforward } \\
\text { like the Lonely } \\
\text { Planet books. } \\
\text { Information reads } \\
\text { like a web article on } \\
\text { mobile. } \\
\text { Spatial Layout: } \\
\text { Separates map }\end{array}$ & $\begin{array}{l}\text { In-app purchase } \\
\text { Location: approximate location } \\
\text { (network-based), precise location } \\
\text { (GPS and network-based) } \\
\text { Phone: read phone status and } \\
\text { identity } \\
\text { Photos/Media/Files: read the } \\
\text { contents of your USB storage, } \\
\text { modify or delete the contents of } \\
\text { your USB storage }\end{array}$ & $\begin{array}{l}\text { Available on both } \\
\text { Android and iOS: } \\
\text { - Android OS } \\
\text { requires version } \\
4.3 \text { and up } \\
\text { - iOS requires } \\
\text { version } 9.0 \text { or } \\
\text { later }\end{array}$ \\
\hline
\end{tabular}




\begin{tabular}{|c|c|c|c|}
\hline & $\begin{array}{l}\text { discovery with } \\
\text { must-see } \\
\text { attractions, enough } \\
\text { white space in } \\
\text { relation to text and } \\
\text { images. }\end{array}$ & $\begin{array}{l}\text { Storage: read the contents of your } \\
\text { USB storage, modify or delete the } \\
\text { contents of your USB storage } \\
\text { Wi-Fi connection information: view } \\
\text { Wi-Fi connections } \\
\text { Device ID \& call information: read } \\
\text { phone status and identity } \\
\text { Other: receive data from Internet, } \\
\text { view network connections, pair with } \\
\text { Bluetooth devices, access Bluetooth } \\
\text { settings, full network access, run at } \\
\text { startup, control vibration, prevent } \\
\text { device from sleeping }\end{array}$ & \\
\hline $\begin{array}{l}\text { Spotted by } \\
\text { Locals }\end{array}$ & $\begin{array}{l}\text { Colour Scheme: } \\
\text { colour coded by } \\
\text { category of things } \\
\text { to do. Each } \\
\text { category once } \\
\text { selected has a } \\
\text { consistent header } \\
\text { colour to remind the } \\
\text { user of the category } \\
\text { they have selected. } \\
\text { Spatial Layout: } \\
\text { Keeps consistent } \\
\text { interactive flow -- } \\
\text { from category, to } \\
\text { map, to all reviews, } \\
\text { to review selection. }\end{array}$ & $\begin{array}{l}\text { In-app purchases } \\
\text { Location: precise location (GPS and } \\
\text { network-based) } \\
\text { Phone: read phone status and } \\
\text { identity } \\
\text { Photos/Media/Files: read the } \\
\text { contents of your USB storage, } \\
\text { modify or delete the contents of } \\
\text { your USB storage } \\
\text { Storage: read the contents of your } \\
\text { USB storage, modify or delete the } \\
\text { contents of your USB storage } \\
\text { Wi-Fi connection information: view } \\
\text { Wi-Fi connections } \\
\text { Device ID \& call connections: read } \\
\text { phone status and identity } \\
\text { Other: receive data from Internet, } \\
\text { view network connections, full } \\
\text { network access, prevent device } \\
\text { from sleeping }\end{array}$ & $\begin{array}{l}\text { Available on both } \\
\text { Android and iOS: } \\
\text { - Android OS } \\
\text { requires version } \\
4.0 .3 \text { and up } \\
\text { - iOS requires } \\
\text { version } 9.0 \text { or } \\
\text { later }\end{array}$ \\
\hline
\end{tabular}




\begin{tabular}{|c|c|c|c|}
\hline Sidekix & $\begin{array}{l}\text { Colour Scheme: } \\
\text { Generally black and } \\
\text { white while using } \\
\text { colour coded } \\
\text { categorical system } \\
\text { for places of things } \\
\text { to do. } \\
\text { Spatial Layout: } \\
\text { Map is always on } \\
\text { screen while using } \\
\text { compass for } \\
\text { direction to walk. } \\
\text { Scroll up for a } \\
\text { closer look at } \\
\text { potential } \\
\text { destination. }\end{array}$ & $\begin{array}{l}\text { Location: approximate location } \\
\text { (network-based), precise location } \\
\text { (GPS and network-based) } \\
\text { Wi-Fi connection information: view } \\
\text { Wi-Fi connections } \\
\text { Other: receive data from Internet, } \\
\text { view network connections, full } \\
\text { network access, run at startup, } \\
\text { prevent device from sleeping }\end{array}$ & $\begin{array}{l}\text { Available on both } \\
\text { Android and iOS: } \\
\text { - Android OS } \\
\text { requires version } \\
4.2 \text { and up } \\
\text { - iOS requires } \\
\text { version } 8.0 \text { or } \\
\text { later }\end{array}$ \\
\hline $\begin{array}{l}\text { Google } \\
\text { Trips by } \\
\text { Google }\end{array}$ & $\begin{array}{l}\text { Colour Scheme: } \\
\text { Consistent with } \\
\text { Google's colours } \\
\text { and branding. } \\
\text { Spatial Layout: } \\
\text { Planning based - } \\
\text { from reservations to } \\
\text { exploring. } \\
\text { Categories for top } \\
\text { rated, nearby, based } \\
\text { on category, kid- } \\
\text { friendly, local } \\
\text { favourites, and } \\
\text { more. Saves most of } \\
\text { screen space for } \\
\text { items rather than } \\
\text { categories or map. }\end{array}$ & $\begin{array}{l}\text { Identity: find accounts on the device } \\
\text { Contacts: find accounts on the } \\
\text { device } \\
\text { Location: precise location (GPS and } \\
\text { network-based) } \\
\text { Other: receive data from Internet, } \\
\text { view network connections, measure } \\
\text { app storage space, full network } \\
\text { access, read sync settings, run at } \\
\text { startup, use accounts on the device, } \\
\text { prevent device from sleeping, } \\
\text { toggle sync on and off, read Google } \\
\text { service configuration }\end{array}$ & $\begin{array}{l}\text { Available on both } \\
\text { Android and iOS: } \\
\text { - Android OS } \\
\text { requires version } \\
4.1 \text { and up } \\
\text { - iOS requires } \\
\text { version } 9.1 \text { or } \\
\text { later }\end{array}$ \\
\hline $\begin{array}{l}\text { City Guides } \\
\text { by } \\
\text { Facebook }\end{array}$ & $\begin{array}{l}\text { Colour Scheme: } \\
\text { Same as Facebook } \\
\text { branding and } \\
\text { mobile app. } \\
\text { Spatial Layout: } \\
\text { Located in } \\
\text { Facebook app in } \\
\text { Apps menu - }\end{array}$ & $\begin{array}{l}\text { Device \& app history: retrieve } \\
\text { running apps } \\
\text { Identity: find accounts on the } \\
\text { device, add or remove accounts, } \\
\text { read your own contact card } \\
\text { Calendar: read calendar events plus } \\
\text { confidential information, add or }\end{array}$ & $\begin{array}{l}\text { Available on both } \\
\text { Android and iOS: } \\
\text { - Android OS } \\
\text { version varies } \\
\text { with device } \\
\text { - iOS requires }\end{array}$ \\
\hline
\end{tabular}




\begin{tabular}{|c|c|c|}
\hline $\begin{array}{l}\text { convenient for users } \\
\text { who already have } \\
\text { Facebook } \\
\text { downloaded onto } \\
\text { their mobile device, } \\
\text { but generally hard } \\
\text { to find without help. }\end{array}$ & 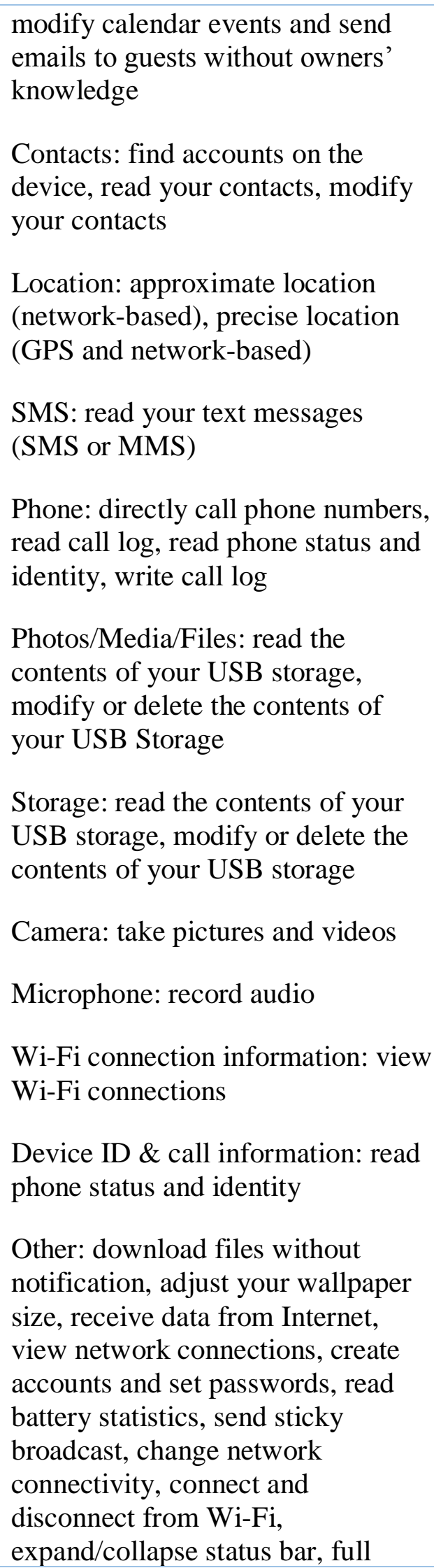 & $\begin{array}{l}\text { version } 8.0 \text { or } \\
\text { later }\end{array}$ \\
\hline
\end{tabular}




\begin{tabular}{|c|c|c|c|}
\hline & & $\begin{array}{l}\text { network access, change your audio } \\
\text { settings, read sync settings, run at } \\
\text { startup, reorder running apps, set } \\
\text { wallpaper, draw over other apps, } \\
\text { control vibration, prevent device } \\
\text { from sleeping, toggle sync on and } \\
\text { off, install shortcuts, read Google } \\
\text { service configuration }\end{array}$ & \\
\hline $\begin{array}{l}\text { Google } \\
\text { Maps }\end{array}$ & $\begin{array}{l}\text { Colour Scheme: } \\
\text { Consistent with } \\
\text { Google's colours } \\
\text { and branding. } \\
\text { Spatial Layout: } \\
\text { Uses map to fill the } \\
\text { entire screen to } \\
\text { serve its } \\
\text { navigational } \\
\text { purpose best, has } \\
\text { sidebar for } \\
\text { directions and other } \\
\text { views, search is } \\
\text { always readily } \\
\text { available. }\end{array}$ & $\begin{array}{l}\text { Device \& app history: retrieve } \\
\text { running apps } \\
\text { Identity: find accounts on the } \\
\text { device, add or remove accounts } \\
\text { Contacts: find accounts on the } \\
\text { device, read your contacts, modify } \\
\text { your contacts } \\
\text { Location: approximate location } \\
\text { (network-based), precise location } \\
\text { (GPS and network-based) } \\
\text { Phone: directly call phone numbers, } \\
\text { read call log, read phone status and } \\
\text { identity, write call log } \\
\text { Photos/Media/Files: read the } \\
\text { contents of your USB storage, } \\
\text { modify or delete the contents of } \\
\text { your USB Storage } \\
\text { Storage: read the contents of your } \\
\text { USB storage, modify or delete the } \\
\text { contents of your USB storage } \\
\text { Microphone: record audio } \\
\text { Wi-Fi connection information: view } \\
\text { Wi-Fi connections } \\
\text { Device ID \& call information: read } \\
\text { phone status and identity } \\
\text { Interification, receive data from } \\
\text { Internet, view configured accounts, }\end{array}$ & $\begin{array}{l}\text { Available on both } \\
\text { Android and iOS: } \\
\text { - Android OS } \\
\text { version varies } \\
\text { with device } \\
\text { - iOS requires } \\
\text { version } 9.0 \text { or } \\
\text { later }\end{array}$ \\
\hline
\end{tabular}




\begin{tabular}{|c|c|c|c|}
\hline & & $\begin{array}{l}\text { view network connections, send } \\
\text { sticky broadcast, connect and } \\
\text { disconnect from Wi-Fi, disable your } \\
\text { screen lock, measure app storage } \\
\text { space, full network access, control } \\
\text { Near Field Communication (NFC), } \\
\text { read sync settings, run at startup, } \\
\text { use accounts on the device, control } \\
\text { vibration, prevent device from } \\
\text { sleeping, toggle sync on and off, } \\
\text { install shortcuts, read Google } \\
\text { service configuration }\end{array}$ & \\
\hline \multicolumn{4}{|c|}{ Figure 4. Competitor App Performance Attributes } \\
\hline & $\begin{array}{l}\text { Compatibility: } \\
\text { What are the claimed features and } \\
\text { why should the user want to use } \\
\text { this app? }\end{array}$ & $\begin{array}{l}\text { Ease of Use: } \\
\text { Incumbent on the } \\
\text { user's satisfaction- } \\
\text { uses app reviews and } \\
\text { rating system to } \\
\text { determine ease of use* }\end{array}$ & $\begin{array}{l}\text { Relative } \\
\text { Advantages: } \\
\text { What makes } \\
\text { this app } \\
\text { standout? }\end{array}$ \\
\hline Yelp & $\begin{array}{l}\text { Restaurant Finder \& Food } \\
\text { Delivery: Dine locally and } \\
\text { discover new places to eat nearby, } \\
\text { make reservations, order pickup or } \\
\text { delivery while viewing menus, } \\
\text { read restaurant reviews from other } \\
\text { users } \\
\text { Review, Discover and Add Photos: } \\
\text { Discover local businesses, } \\
\text { restaurants and other services, look } \\
\text { up addresses and phone numbers, } \\
\text { read and write reviews, browse } \\
\text { photo gallery and add photos of } \\
\text { experience, redeem great check-in } \\
\text { offers } \\
\text { Car Repair, Shopping and Other } \\
\text { Services: Discover hottest } \\
\text { shopping spots; hire local } \\
\text { professionals for car repair, travel, } \\
\text { and home renovations, etc.; filter } \\
\text { searches by neighbourhood, }\end{array}$ & $\begin{array}{l}\text { Rated } 4.3 \text { on Google } \\
\text { Play (Android) from } \\
352,750 \text { ratings } \\
\text { (Last updated: August } \\
\text { 11, 2017) } \\
\text {--- }\end{array}$ & $\begin{array}{l}\text { "Yelp has over } \\
100 \text { million } \\
\text { restaurant and } \\
\text { business } \\
\text { reviews } \\
\text { worldwide, as } \\
\text { well as tons of } \\
\text { additional } \\
\text { features to help } \\
\text { you find the } \\
\text { services that } \\
\text { you're looking } \\
\text { for." }\end{array}$ \\
\hline
\end{tabular}




\begin{tabular}{|c|c|c|c|}
\hline & $\begin{array}{l}\text { distance, rating, price, location and } \\
\text { hours of operations }\end{array}$ & & \\
\hline TripAdvisor & $\begin{array}{l}\text { Compare prices from } 200+\text { hotel } \\
\text { booking sites to find lowest price } \\
\text { on right hotel; Browse millions of } \\
\text { reviews, opinions, videos and } \\
\text { candid photos by travelers; Find } \\
\text { best hotel (including Travelers' } \\
\text { Choice award winners); Explore } \\
\text { restaurants by food type, price } \\
\text { range, and rating; Discover cool } \\
\text { things to do; Compare airfares and } \\
\text { find great deals; Discover options } \\
\text { nearby; Get answers to specific } \\
\text { travel questions in forums; Add } \\
\text { reviews and photos; Download } \\
\text { maps and reviews from over } 300 \\
\text { cities worldwide onto phone for } \\
\text { free (avoiding data roaming) }\end{array}$ & $\begin{array}{l}\text { Rated } 4.4 \text { on Google } \\
\text { Play (Android) from } \\
\text { 1,055,361 ratings } \\
\text { (Last updated: August } \\
\text { 10, 2017) } \\
\text {--- } \\
\text { Rated } 4 \text { on iTunes App } \\
\text { Store from 9,784 } \\
\text { ratings - all versions } \\
\text { (Last updated: August } \\
\text { 3, 2017) }\end{array}$ & $\begin{array}{l}\text { "TripAdvisor } \\
\text { makes it easy } \\
\text { to find the } \\
\text { lowest airfare, } \\
\text { best hotels, } \\
\text { great } \\
\text { restaurants, } \\
\text { and fun things } \\
\text { to do, } \\
\text { wherever you } \\
\text { go. And } \\
\text { booking } \\
\text { options for } \\
\text { hotels, } \\
\text { restaurants and } \\
\text { flights are just } \\
\text { a tap away." }\end{array}$ \\
\hline $\begin{array}{l}\text { Guides by } \\
\text { Lonely } \\
\text { Planet }\end{array}$ & $\begin{array}{l}\text { Expert-curated City Guides: } \\
\text { Writers review every place } \\
\text { carefully and offer essential tips } \\
\text { and advice on where to stay, what } \\
\text { to do and where to eat to discover } \\
\text { off-the-beaten-track places. } \\
\text { Top Recommendations: Sorts } \\
\text { through cluttered data of options to } \\
\text { refine the spots worth seeing, as } \\
\text { chosen by travel experts. } \\
\text { Offline Maps: Maps and } \\
\text { phrasebooks works while you're } \\
\text { offline to avoid roaming charges. } \\
\text { Audio Phrasebooks: More than } \\
10,000 \text { phrases in } 19 \text { different } \\
\text { languages available. } \\
\text { Simple Bookmarking: Save and } \\
\text { organize favourite hotels, } \\
\text { restaurants and things to do so you } \\
\text { can visit (or revisit) must-sees. }\end{array}$ & $\begin{array}{l}\text { Rated } 4.6 \text { on Google } \\
\text { Play (Android) from } \\
6,402 \text { ratings } \\
\text { (Last updated: August } \\
\text { 7, 2017) } \\
\text {--- } \\
\text { Rated } 4.5 \text { on iTunes } \\
\text { App Store from } 81 \\
\text { ratings - all versions } \\
\text { (Last updated: August } \\
8,2017 \text { ) }\end{array}$ & $\begin{array}{l}\text { As the world's } \\
\text { leading travel } \\
\text { content } \\
\text { provider, the } \\
\text { advantage lies } \\
\text { in its } \\
\text { reputation and } \\
\text { loyalty to } \\
\text { potential users. } \\
\text { Includes 100+ } \\
\text { cities, with } \\
\text { new ones } \\
\text { added } \\
\text { "constantly." }\end{array}$ \\
\hline
\end{tabular}




\begin{tabular}{|c|c|c|c|}
\hline & Currency converter $\&$ helpful tips & & \\
\hline $\begin{array}{l}\text { Spotted by } \\
\text { Locals }\end{array}$ & $\begin{array}{l}\text { Regular updates on newly spotted } \\
\text { local gems } \\
100 \text { per cent offline - no Internet } \\
\text { required } \\
\text { Full city maps } \\
\text { Lists spots nearby \& navigate } \\
\text { offline } \\
\text { Save your favourite tips } \\
\text { Available for } 67 \text { cities in Europe } \\
\text { and North America }\end{array}$ & $\begin{array}{l}\text { Rated } 4.6 \text { on Google } \\
\text { Play (Android) from } \\
241 \text { ratings } \\
\text { (Last updated: August } \\
\text { 9, 2017) } \\
\qquad--- \\
\text { Rated } 3.5 \text { on iTunes } \\
\text { App Store from } 10 \\
\text { ratings - all versions } \\
\text { (Last updated: June 5, } \\
\text { 2017) }\end{array}$ & $\begin{array}{l}\text { Individual city } \\
\text { guides } \\
\text { specifically } \\
\text { made for locals } \\
\text { and curated } \\
\text { only by locals. } \\
\text { Must purchase } \\
\text { each city guide } \\
\text { separately. } \\
\text { No tourists, } \\
\text { highlights, } \\
\text { only insider } \\
\text { guide. }\end{array}$ \\
\hline Sidekix & $\begin{array}{l}\text { Better Navigation: Create and } \\
\text { personalize your own route by } \\
\text { adding exactly the places you want } \\
\text { to visit } \\
\text { Trip Planner: Explore other parts } \\
\text { of town or discover a different city } \\
\text { from afar } \\
\text { World Travel Guide: Available in } \\
\text { hundreds of cities worldwide } \\
\text { Sightseeing: Discover unique } \\
\text { attractions, urban gems, and walks, } \\
\text { as recommended by local bloggers } \\
\text { Nearby Attractions: See cool } \\
\text { nearby attractions on the map } \\
\text { during your journey } \\
\text { Things to Do: Find new places and } \\
\text { fun thing to do on the fly } \\
\text { Best Places: Curated } \\
\text { recommendations show highest } \\
\text { rated things nearby }\end{array}$ & $\begin{array}{l}\text { Rated } 4.6 \text { on Google } \\
\text { Play (Android) from } \\
160 \text { ratings } \\
\text { (Last updated: August } \\
\text { 2, 2017) } \\
\qquad--- \\
\text { Not enough ratings to } \\
\text { display an average on } \\
\text { iTunes App Store } \\
\text { (Last updated: August } \\
\text { 15, 2017) }\end{array}$ & $\begin{array}{l}\text { "Loved by } \\
\text { locals and } \\
\text { travellers alike, } \\
\text { Sidekix smart } \\
\text { walking } \\
\text { navigation } \\
\text { offers a choice } \\
\text { of sightseeing } \\
\text { routes based on } \\
\text { interests and } \\
\text { itinerary, } \\
\text { whether } \\
\text { shopping, } \\
\text { restaurants, } \\
\text { culture, } \\
\text { nightlife, and } \\
\text { other } \\
\text { attractions to } \\
\text { explore." }\end{array}$ \\
\hline
\end{tabular}




\begin{tabular}{|c|c|c|c|}
\hline & $\begin{array}{l}\text { Nearby Events: Find upcoming } \\
\text { events in real-time } \\
\text { Location Sharing: Easily share } \\
\text { local finds and send routes directly } \\
\text { to friends } \\
\text { Personalized City Maps: Follow } \\
\text { guides and maps of friends and } \\
\text { influencers }\end{array}$ & & \\
\hline $\begin{array}{l}\text { Google } \\
\text { Trips by } \\
\text { Google }\end{array}$ & $\begin{array}{l}\text { Automatic Trip Organization: } \\
\text { Reservations automatically } \\
\text { gathered from Gmail and } \\
\text { organized into individual trips. } \\
\text { Each trip contains plans, things to } \\
\text { do, food and drink suggestions, and } \\
\text { more. } \\
\text { Bundled Reservations: See flight, } \\
\text { hotel, rental car, and restaurant } \\
\text { bookings in one place } \\
\text { Day Plans: Find popular plans } \\
\text { organized on a map that you can } \\
\text { customize based on interests and } \\
\text { available time. } \\
\text { Nearby Attractions: Find what's } \\
\text { popular nearby (and whether } \\
\text { they're open) as well as reviews } \\
\text { and ratings from other travellers. } \\
\text { Things to Do: Every trip has this } \\
\text { feature organized into useful } \\
\text { categories with local suggestions } \\
\text { and travel tips. } \\
\text { Offline Access } \\
\text { "Getting Around" section offers } \\
\text { helpful transportation information } \\
\text { "Need to know" section offers } \\
\text { information on health and }\end{array}$ & $\begin{array}{l}\text { Rated } 4.1 \text { on Google } \\
\text { Play Store (Android) } \\
\text { from } 17,793 \text { ratings } \\
\text { (Last updated: July 28, } \\
\text { 2017) } \\
\text {--- } \\
\text { Rated } 2.5 \text { on iTunes } \\
\text { App Store from } 50 \\
\text { ratings } \\
\text { (Last updated: June 29, } \\
\text { 2017) }\end{array}$ & $\begin{array}{l}\text { Created by } \\
\text { Google. } \\
\text { Created to } \\
\text { make } \\
\text { "exploring the } \\
\text { world easier by } \\
\text { organizing } \\
\text { your essential } \\
\text { info in one } \\
\text { place and } \\
\text { making it } \\
\text { available even } \\
\text { offline. Get } \\
\text { activity } \\
\text { suggestions } \\
\text { based on } \\
\text { what's nearby, } \\
\text { customizable } \\
\text { day plans, and } \\
\text { your travel } \\
\text { reservations } \\
\text { from Gmail." }\end{array}$ \\
\hline
\end{tabular}




\begin{tabular}{|c|c|c|c|}
\hline & $\begin{array}{l}\text { emergencies, shopping, currency } \\
\text { and tipping info and Internet }\end{array}$ & & \\
\hline $\begin{array}{l}\text { City Guides } \\
\text { by } \\
\text { Facebook }\end{array}$ & $\begin{array}{l}\text { "Calls together personalized } \\
\text { recommendations for travellers, } \\
\text { based on where locals go and } \\
\text { where their friends have previously } \\
\text { visited." } \\
\text { Users "see locations friends have } \\
\text { visited in that city" and } \\
\text { recommend "place the locals go." } \\
\text { Facebook will "pull out words that } \\
\text { people use most often to talk about } \\
\text { that place." } \\
\text { "City Guides will also pull data } \\
\text { and information from the places it } \\
\text { recommends. If a user comes } \\
\text { across a spot they're interested in, } \\
\text { they will be redirected to that } \\
\text { Facebook page, where they may } \\
\text { see a 'book now' or "contact' } \\
\text { option that allows users to book a } \\
\text { hotel, make a restaurant } \\
\text { reservation, or message a store } \\
\text { quickly and straight from the app." } \\
\text { (Travel and Leisure, 2017) }\end{array}$ & $\begin{array}{l}\text { Rated } 4 \text { on Google } \\
\text { Play Store (Android) } \\
\text { from } 69,343,579 \\
\text { ratings** } \\
\text { (Last updated: August } \\
\text { 14, 2017) } \\
\qquad--- \\
\text { Rated } 3.5 \text { on iTunes } \\
\text { App Store from } \\
\text { 294,213 ratings - all } \\
\text { versions** } \\
\text { (Last updated: August } \\
\text { 10, 2017) }\end{array}$ & $\begin{array}{l}\text { Within the } \\
\text { Facebook app. }\end{array}$ \\
\hline $\begin{array}{l}\text { Google } \\
\text { Maps - } \\
\text { Navigation } \\
\text { \& Transit }\end{array}$ & $\begin{array}{l}\text { Real-time updates; beat traffic with } \\
\text { real-time navigation; ETAs and } \\
\text { traffic conditions; real-time transit } \\
\text { info; save time with automatic re- } \\
\text { routing based on live traffic, road } \\
\text { closures and traffic incidents; } \\
\text { navigation lane guidance so you } \\
\text { don't miss a turn or exit; find pit } \\
\text { stops } \\
\text { Discover places and explore like a } \\
\text { local; find top-rated restaurants and } \\
\text { local businesses; decide on places } \\
\text { to go with reviews, ratings, and } \\
\text { pictures of foods and interiors; plan }\end{array}$ & $\begin{array}{l}\text { Rated } 4.3 \text { on Google } \\
\text { Play Store (Android) } \\
\text { from } 8,199,586 \text { ratings } \\
\text { (Last updated: August } \\
9,2017 \text { ) } \\
\text {--- } \\
\text { Rated } 4.5 \text { on iTunes } \\
\text { App Store from } 24,024 \\
\text { ratings - all versions } \\
\text { (Last updated: August } \\
\text { 14, 2017) }\end{array}$ & $\begin{array}{l}\text { Created by } \\
\text { Google.G } \\
\text { Automatically } \\
\text { downloaded } \\
\text { into every } \\
\text { Android and } \\
\text { iOS device } \\
\text { upon purchase. }\end{array}$ \\
\hline
\end{tabular}




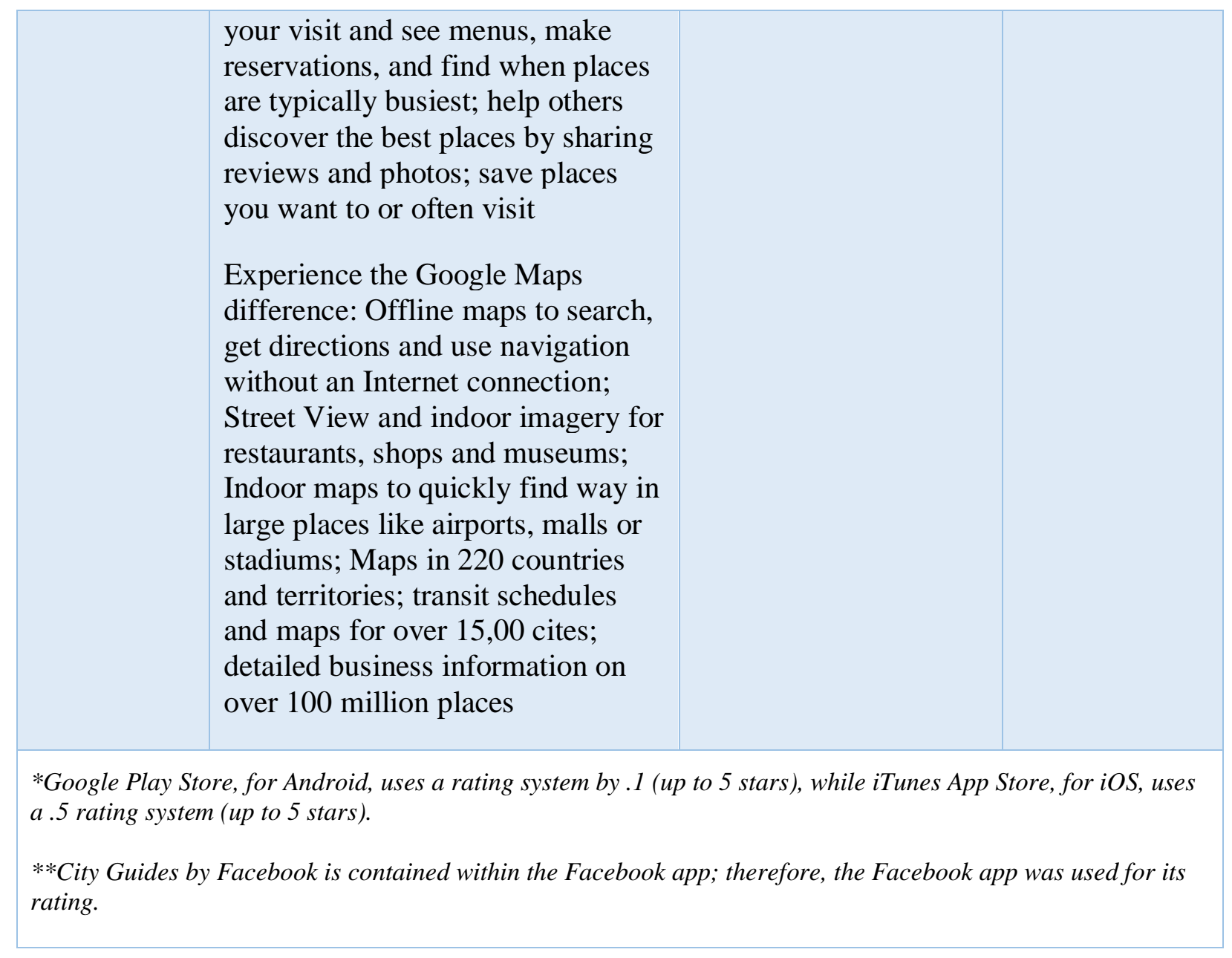




\section{Evaluation / Findings}

\subsection{Literature review findings}

Through research on navigation and digital mapping it was found that database technology can reinvent the ways in which people occupy and create physical and conceptual space (Rice, 2008). With databases continuously growing, information of all sorts takes up digital space. With reference to Google Maps, much of navigational digital space has not been as personalized as it could be. This is where there is a gap in current mobile travel apps. With every new destination a traveller experiences, their identity continues to grow and change. This variable, Rice explains, depends on the traveller's access to their own database (2008). Therefore, when a traveller is also a user of a mobile travel app, the identity of that person turns into a digital profile - a digital profile with more meaning to the newly discovered place or destination. When using a mobile travel app for discovery purposes, the competitive analysis found that a user will experience top rated "things to do" in a new city as their first interactions with the app. It is through the personalization of interests and the application of personal data during the user's first interaction with the app that allows the user to recognize popular sights, restaurants, nearby services, and useful travel information. This aggregated information of past travels shapes the interests of the current traveller, while continuously affecting travel plans in the user's future. As city sights are rated by users, the traveller is able to gain a better understanding of their own identity within a city and what they will enjoy in other cities. These engagements are useful for the traveller and should they be accurately tracked. As time consuming as it is for the user to continually be tracking their journey in a new city, this will ultimately enhance future journeys to come. The memories and meaning, Rice highlights, are part of the traveller's reflection process after a journey (1960). The literature review found that a trip profile before sign up is key for 
personalizing DROP/PIN. Lau and McKercher's research on tourist movement patterns has suggested potential questions to ask in the setup survey for new users (2006). Movement patterns are reflected based on trip profile, personal motives, physical configurations of destination, prior visitation and time (Lau and McKercher, 2006). DROP/PIN's analysis of trip profile and physical configurations cannot be adjusted; therefore, personalization lies in recognizing the traveller's personal motives, prior visitation and time available at each destination.

\subsection{Competitor analysis findings}

By using the research model to complete the competitive analysis of current mobile travel apps produced findings in each app attribute category. To reiterate, the app attributes analyzed are:

1. User interface attractiveness,

2. Privacy \& security,

3. Portability,

4. Compatibility,

5. Ease of use, and

6. Relative advantage

The competitive analysis found that colour scheme and spatial layout of the user interface attractiveness was commonly on brand with the logo or used a rainbow colour-coding system for categories, as there were many categories to choose - from restaurant selection to nightlife or shopping. Those apps with a spatial layout that included a map as a main feature (Google Maps, Sidekix, and Spotted by Locals) were mostly featured for the purpose of finding nearby attractions. This describes a navigation-first approach. Those with a list view of recommendations as the prominent feature included Yelp, TripAdvisor, and Google Trips by Google. This describes a recommendation-first approach. The rest of the competitors (City Guides by Facebook and Guides by Lonely Planet) chose the destination as the main feature for 
the user to select first, which is a discovery-first approach. With this information, the user's first interaction with the mobile travel app can be separated into three categories for the user: navigation-first, recommendation-first, and discovery first approaches. Based on these three classifications of approaches, the ease of use attribute, which is incumbent on the user's satisfaction, was then analyzed through both Android ratings on the Google Play Store and iOS ratings found on the iTunes App Store. Fig. 5 shows the findings:

\section{Figure 5: User Satisfaction of Mobile Travel Apps Based on Interface Approach}

\begin{tabular}{|c|c|c|c|}
\hline & $\begin{array}{l}\text { Navigation-first } \\
\text { Approach }\end{array}$ & $\begin{array}{l}\text { Recommendation-first } \\
\text { Approach }\end{array}$ & $\begin{array}{l}\text { Discovery-first } \\
\text { Approach }\end{array}$ \\
\hline $\begin{array}{l}\text { Android } \\
\text { Rating }\end{array}$ & 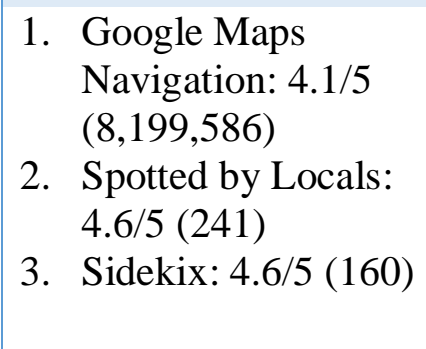 & $\begin{array}{l}\text { 1. TripAdvisor: } 4.4 / 5 \\
(1,055,361) \\
\text { 2. Yelp: } 4.3 / 5(352 \text {, } \\
750) \\
\text { 3. Google Trips by } \\
\text { Google: } 4.1 / 5 \\
(17,793)\end{array}$ & $\begin{array}{l}\text { 1. Guides by Lonely } \\
\text { Planet: } 4.6 / 5 \\
(6,402) \\
\text { 2. City Guides by } \\
\text { Facebook: } 4 / 5 \\
(69,343,579)\end{array}$ \\
\hline iOS Rating & $\begin{array}{ll}\text { 1. } & \text { Google Maps } \\
& \text { Navigation: } 4.5 / 5 \\
& (24,024) \\
\text { 2. } & \text { Spotted by Locals: } \\
& 3.5 / 5(10) \\
\text { 3. } & \text { Sidekix: Ratings not } \\
\text { available }\end{array}$ & $\begin{array}{ll}\text { 1. TripAdvisor: } 4 / 5 \\
(9,784) \\
\text { 2. Yelp: } 3.5 / 5(9,029) \\
\text { 3. Google Trips by } \\
\text { Google: } 2.5 / 5(50)\end{array}$ & $\begin{array}{l}\text { 1. City Guides by } \\
\text { Facebook: } 4.5 / 5 \\
(24,024) \\
\text { 2. Guides by Lonely } \\
\text { Planet: } 4.5 / 5(81)\end{array}$ \\
\hline $\begin{array}{l}\text { Highest Rated } \\
\text { After Analysis }\end{array}$ & Google Maps & TripAdvisor & $\begin{array}{l}\text { Guides by Lonely } \\
\text { Planet }\end{array}$ \\
\hline
\end{tabular}

In the findings [Fig. 5], all eight of the apps analyzed have been narrowed down to the top three highest rated apps by category. This allows for a quantitative method analysis of the competitors. The apps are ordered first by rating, then by amount of ratings. This means that, in this analysis, if ratings are tied, the app with more reviews is bumped to a higher rating spot. 
Overall, Android devices received more user/consumer ratings than iOS users. It should be noted again that in the discovery-approach first column, City Guides by Facebook data is not contingent on the feature of City Guides itself, but rather that of the Facebook app as a whole. Because of this, user ratings are skewed. However, it's interesting to note that while City Guides by Facebook has many more ratings, it still does not surpass the Android rating of Guides by Lonely Planet. This can mean that while only 6,402 Android users have rated the app, they are users that are most satisfied amongst all of the mobile travel apps in the analysis. This is especially notable because the ratings are similarly high in the iOS rating of the same column. Again, this is a sign of trusted users; therefore, suggesting higher user engagement. Another factor regarding ratings and, by association, ease of use, is the date of the latest update. This shows how viable each app is because it regards the frequency at which developments are being made. Observations of latest update were made on Tuesday, August 15, 2017:

\section{Updates within the past week (August 8 - 15, 2017):}

Android: Yelp (Aug 11), TripAdvisor (Aug 10), Spotted by Locals (Aug 9), City Guides by Facebook (Aug 14), and Google Maps (Aug 9)

iOS: Yelp (Aug 14), Guides by Lonely Planet (Aug 8), Sidekix (Aug 15), City Guides by Facebook (Aug 10), and Google Maps (Aug 14)

Updates within the past month (July 18 - August 15, 2017):

Android: Guides by Lonely Planet (Aug 7), Sidekix (Aug 2), Google Trips (July 28) iOS: TripAdvisor (Aug 3)

Updates over a month ago (before July 18, 2017):

iOS: Spotted by Locals (June 5), Google Trips (June 29) 
Based on these observations, Yelp, City Guides by Facebook, and Google Maps were updated most frequently across both operating systems. These observations also found that iOS updates were updated less frequently than Android updates. If these observations are further cross-referenced with user satisfaction of interface attractiveness [Fig. 5], Google Maps would lead in app effectiveness for a user as it is the only one in the top three choices of each analysis. However, because DROP/PIN takes a discovery-based approach in its implementation, Guides by Lonely Planet would lead in app effectiveness for discovery purposes. Discovery purposes, in this case, means information about places and sights within a destination.

Permissions of each app were used to analyze privacy and security. They are the extent to which a user's data is going to be used in the app, whether it be modified or disclosed at all (J. Fang et al., 2017). The permissions were given categories on the Google Play Store, although not all mobile apps possess each permission. The categories are: identity, contacts, location services, phone, photos/media/files, storage, camera, microphone, in-app purchases, Wi-Fi connection information, device ID and call information, calendar, SMS, and other. Google Maps and City Guides (Facebook) had the most permissions. These permissions will be used and further explained in DROP/PIN implementation in the conclusions section.

Portability, referring to the operating systems used and available for different mobile devices do not vary much between the mobile travel apps. This section compares Android and Apple operating systems. Android is currently on its OS version 7.0 "Nougat," which was originally released at the end of August in 2016 (Android, 2017). Apple is currently on iOS version 10, with plans for iOS 11 to be released in fall 2017 (Apple, 2017). Most iOS (Apple) apps require version 9.0 or later, with the exception of two (City Guides by Facebook and Sidekix) requiring 8.0 and one (Google Trips) requiring version 9.1 or later. The Android OS 
varies more between apps. The Android OS is used on a variety of mobile devices (unlike Apple's only mobile device, the iPhone); therefore, has more complex development. Apps such as Yelp, TripAdvisor, City Guides by Facebook and Google Maps use different versions depending on the mobile device of the user; therefore, it's not clear which version is used most. Guides by Lonely Planet uses Android OS 4.3 and up; Spotted by Locals uses version 4.0.3 and up; and Google Trips uses version 4.1 and up. This doesn't give much pertinent information into the development of DROP/PIN, but focuses rather on improving and building as a company. It shows that it's best to keep updates and improvements of OS consistent across all devices to avoid losing user engagement should the user switch devices.

Compatibility is the users' perception of how the app fits into travel needs and preferences (J. Fang et al., 2017). This, to a degree, can be analyzed through current ratings and features. Compatibility, in this context, describes the features and experiences each app claims to give its users. This information was taken from each competitor's profile on the Google Play Store and iTunes Store, as this is where users go to find out if the app is a good match for them. In comparison, relative advantage is partially in tandem with compatibility. All of the existing apps except for Spotted by Locals and Sidekix have recognition in the travel and/or technology industry. They are trusted and reliable companies in the market already. Spotted by Locals and Sidekix; however, have to stand out from the competition in a different way. Spotted by Locals, though still a discovery app, allows the user to discover their own city through other locals. It allows locals to get to know their city better. Sidekix, which is arguably the most similar to DROP/PIN, is for both travellers and locals. It creates an itinerary through as-you-go personalization but doesn't add the social tools nor creates a trip profile and persona (a traveller's digital identity) like DROP/PIN does. 


\section{Conclusions}

The final conclusion drawn from this research supports the implementation of the personalized mobile travel app DROP/PIN. In this section DROP/PIN's main features of design, technology, performance and social networking components will be further explained. Limitations of this research, like any other, are present and will be explained after implementation in order to suggest points that were not addressed from research, analysis and implementation. Finally, suggestions for future work involve research and development in the form of user surveys and focus groups. This would further increase a traveller's digital identity through personalization.

This research found that multiple factors effect a traveller's digital identity. It can be concluded that personalization of data systems inputting from the user while travelling is needed to allow a mobile travel app user to navigate a new destination more effectively. Personalization leads to higher user engagement, which leads to better business and more users for the app. Part of personalization lies in social interactions with other users in the form of photo sharing and reviews or comments, as proven through both secondary research and the competitive analysis that was conducted on mobile travel apps in the current market. The end game for DROP/PIN is user engagement, which aims in answering the question: What do travellers want in a travel app? And, without the traveller/user knowing, the question for the app developers becomes: How can we define a traveller's digital identity in one app?

After tracking findings in mobile travel apps, it can be concluded that:

1. More user-based personalization is needed in navigational apps for discovery purposes. 
2. Personalization is best if a trip profile (or traveller's digital identity) of the user's interests is built upon first interaction with the mobile travel app.

3. After building a profile, personalization is further tracked and tailored with social engagement and user's interactions within the app.

4. The ease of use attributes reflects user's overall satisfaction, which can be gauged through consumer/user reviews and ratings of each app.

5. The user satisfaction model for mobile travel app interfaces is classified into three different approaches: navigation-first, recommendation-first, and discovery-first.

6. While Google Maps proves to be most user effective based on the competitive analysis across all categories, Guides by Lonely Planet leads in user effectiveness for a discovery-first approach.

7. Privacy and security permissions are most complex when implementing a new app because they rely on the most cooperation of both parties involved (the company and the user).

8. Operating systems should be updated and improved upon across all mobile devices as best as possible to ensure the effective portability.

As displayed in this research, there are a number of components at work when determining what the traveller, as a user, expects from a mobile travel app. Through paying close attention to and implementing these proven theories a successful app is possible. The next step is to understand DROP/PIN's features and how it relates to the research. 


\subsection{Purpose}

The purpose of this research is to better understand the traveller in the context of a digital user. This means tracking and tailoring discovery options towards the traveller as a user. Research shows that personalization, social interactions, as well as app design and performance effect the user's engagement; therefore, the purpose of DROP/PIN lies in advancing these factors in the development phase, while also sustaining them as the business is up and running. As with many beginnings of startups and small businesses, a mission, vision and values should be one of the first aspects to consider upon launching. This helps the user understand DROP/PIN's goals and helps in sustaining long-term developments.

Mission: To create a community of travellers (with a smartphone) while allowing continuous personalization for discovering new urban destinations through social and interactive engagement.

Vision: To create a traveller's digital identity in an app that encourages exploration and allows young travellers to connect to new experiences and social interactions around the globe.

Values: Always evolve - in the latest technology, digital strategy and market assessments; Promote exploration - creating user-friendly navigation and provide incentives; Embrace openness - operating on user feedback and consumer reviews to advance user engagement; Celebrate culture - allow for recognition of diversity worldwide through shared interests, perspectives, and identity; Create global citizens - through social interactions and added experiences, traveller's gain a better outlook and understanding of worldly events. From this core recognition, along with the research of from this paper, DROP/PIN's interface and user experience can now be established. 


\subsubsection{Interface Design}

The design of DROP/PIN began with the idea that personalization and location settings can provide a traveller with a better trip profile and itinerary. This is possible through a couple ways. First, upon sign up, the user will have to complete an initial preference questionnaire to build a travel profile. This allows the app to understand the user's digital identity as a traveller. As mentioned, with each trip, an algorithm is used to continuously build upon destinations in the user's previous trip. The initial travel profile narrows down travel interests and favourite activities per city.

After signing up with a username and password, the travel profile starts with the basics of the user: Name, current city/region, age (optional), and photo (optional). The next section is used to identify travel interests. Some travel interest categories include: local history, art and culture, local cuisine, local nightlife, markets and shopping. After approving this selection, it sends the user to favourite activities. This list includes: extreme sports, leisure activities, books and literature, outdoor activity, indoor activity, innovation and technology, artistic events. The third selection is the user's next trip selection and length. This section; however, can be skipped if the user is still undecided on a destination and wishes to browse options. Once the basic profile is made, the user can edit it at any time. This includes editing previous travel history (including places lived and for which years) as well as a trip wish list. The travel profile is located at the top right-hand corner of the screen at all times.

Once complete, the user can begin exploring options. The search bar is located at the top of the screen at all times, which is where the user can search your next trip by "where and when" at any time and create a trip name that will be shown in the Trips tab. The tabs on the homepage 
are: "For You," which is the list version of destinations and experiences to choose from based on your travel profile. Scrolling down this list also brings up the list version of most visited, followed by nearby destinations and experiences. The next tab is "Nearby," which brings up the map view of destinations and experiences based on the user's current location and travel profile. Similar to SnapMap, the user will see clickable bubbles or "hot spots" of recommended current events and attractions selected through the most recent Instagram posts that have been geotagged to said hot spot. One click on this bubble will allow the user to see the current posts. The tap and hold option brings up the corresponding link to information for the attraction or event. Most notable about this feature is that the user can allow for notifications when you are within $100 \mathrm{~km}$ of a potential interest. The notification will read: "Hot Spot Nearby" followed by "Category (ex. Markets \& Shopping - Activity (ex. Vintage Shopping) - Name of Place/Attraction (ex. Kensington Market)." This allows the user to screen the area for current happenings through Instagram posts before deciding to visit. In the map view, the user is able to toggle between views titled "For You," "Most Visited," "Local Events" and "See all," which enables the user to better visualize a planned itinerary for each city. In the "Nearby" tab and the "For You" tab the user can add a destination to any of your created trips. This feature helps the user plan a trip by also editing the length of your trip should there be more additions or subtractions to your trip. The third tab is "Places," allowing the user to browse potential cities to visit based on interests. The fourth tab is "Trips," where the user can see upcoming trips and itinerary. It also gives the user the option to add travel buds and update the length, dates, and base location (meaning the location of your accommodation). Throughout the trip this page allows you to write notes on each destination, event or sight the user has visited. Once completed, the trip is then "scrapbooked" in the Trips tab for the user to reflect on or add notes for future reference or 
reflection. The last tab is "Buds." This section allows the user to create social relationships with travelling friends, while also giving them the opportunity to make new ones. The friends list is ordered with known/added friends at the top followed by a list of users nearby who have compatible travel profiles. Based on the user's profile settings, they are able to instant message potential travel "buds" without completely exposing their entire identity. This feature allows travellers to make connections abroad, or within their own city, depending on how they choose to use DROP/PIN. Only buds with 70 per cent compatibility or higher are displayed to reduce a surplus of information for the user. Through this feature, travellers create a diverse global network of people with likeminded interests.

\subsubsection{Technology and permissions}

DROP/PIN would not be able to operate without the use of algorithms for personalization. The ADaPT system, as mentioned in the literature review of this research, is the system that allows the app to collect data on the users' choices. Every query from the user helps to collect and understand the users' identity. Along with this personalization system, there are permissions that were stated in the competitive analysis that regard app privacy and security.

Having listed what all the competitors encompass, DROP/PIN would need to have the following permissions for it to operate:

- Location: precise location (GPS and network-based)

- Identity: read phone status and identity, find accounts on the device (to sync with "buds" and interests), read your contacts, and modify your contacts

- Photos/Media/Files: read the contents of your USB storage, modify or delete the contents of your USB storage 
- Wi-Fi connection

- Other: Receive data from Internet, view network connections, control Near Field Communication (NFC), toggle sync on and off, run at startup, full network access, prevent device from sleeping

Overall, it's important to note that these permissions are ongoing because the DROP/PIN prototype is still in development.

\subsection{Limitations}

Throughout any research there will be limitations of data and findings. This research solely used one research model for the analysis of completion in mobile travel apps used for discovery purposes. The apps to analyze were chosen based on popularity in the current market. The competitors were selected because of their main features included discovery, navigational and recommendation properties. The majority of the competitors chosen reflect that of a discovery feature; however, basic navigation and recommendation associations were chosen to support DROP/PIN's main focus of discovery. As seen through this analysis, the competitors have an overlap in features for the purpose they serve. While some apps, such as Yelp and TripAdvisor, reflect the recommendation approach, they are mostly based on consumer reviews in a sharing economy. The sharing economy is a way for consumers to share existing resources through a market catalyzed by disruptive technologies (Darcy, 2015). Though this generally occurs between private buyers and private sellers, the sharing economy includes the sharing of information, which comes in the form of reviews in this case. This information sharing is comprised of users whom have previously discovered a destination. The sharing economy relies 
on consumer reviews for it to thrive. Knowledge of frequents, motives and behaviours of digital information sharing in the form of reviews is not addressed in this research.

Another limitation that was found once developing DROP/PIN lied in the instant messaging and social interactions of travellers who are strangers to one another. The comfortability within anonymous profiles and individuals' communication presents a limitation. More specifically, more research is needed in recognizing motives of anonymous communication through social media when across cultures and for travel purposes. This could be research into the history of online chat rooms and applications such as MSN, as well as large anonymous forums such as Reddit.

In terms of technology research, there are limitations in the extent of explaining all components of technology involved in DROP/PIN as an app as this research primarily focuses on design and performance from a user point of view. As described, DROP/PIN will use an Instagram API (application program interface), GPS for location services, and the listed permissions described above for its development. However, the app is currently in the development stage and is a live prototype; therefore, limitations in technology advancements continue to exist.

When discussing competition for DROP/PIN, one of the limitations is also non-digital. Analysis of tour guiding companies presents itself as competition. City walking tours, as well as boat or bus tours provide a face-to-face interaction for travellers that is not guaranteed in a digital app. Tour guides are usually locals in each city; therefore, they can offer tips and recommendations that are trusted among tourists. This is another clear competitor for any mobile travel app, including DROP/PIN. 


\subsection{Future work}

Although a comprehensive research analysis and study on user engagement for mobile travel apps was performed, there will continually need to be research conducted to adapt to the ever-changing digital landscape. Regarding digital media ecosystems, there is constant changing with what the consumer/user wants. The most important element to factor into future work is understanding the user's feedback and habits. Improvements should be made cautiously and frequently. Travel apps pose more need for quick adaptation and implementation of user

feedback because of popular destinations and updates of sights, or events continuously changing. In addition, political and cultural dispositions around the world combined with natural occurrences (natural disasters, revolutions) will ultimately influences where people choose to travel.

The limitations of this research can also be part of its future work. Research in the limitations can be conducted in order to improve DROP/PIN's user engagement. This means future analysis on digital and non-digital competitors, research on instant messaging behaviour with anonymous users, and the workings of all technology and algorithms involved in building DROP/PIN. The most significant notion of this research and research to come is knowing that the traveller's digital identity never truly ends. It is only when the traveller stops discovering new places, new sights, and new events that the journey is forever scrapbooked in a digital space. The journey is what DROP/PIN aims to imprint. Every interaction advances the traveller's digital identity within the proposed app, DROP/PIN. Furthermore, the users' behaviour and engagement will always be key to continuing research and development. 


\section{References}

Allen, D. (2015). The Sharing Economy. Institute of Public Affairs, 67(3). 24-27.

Apple Inc. (2017). iOS 10 (Version 10). [Software]. Available from https://www.apple.com/ca/ios/ios-10/

Buxton, M. (2017, July 27). Snapchat's “Snap Map” Will Transform How You Connect With Friends. Retrieved from http://www.refinery29.com/2017/06/160113/snapchat-snapmap-location-update

Chokkattu, J. (2017, July 25). The world can be your oyster with these great travel apps. Retrieved by https://www.digitaltrends.com/mobile/best-travel-apps/2/

Cohen, E. (1972). Toward a Sociology of International Tourism. Social Research, 39, 164-182. Retrieved from https://www.jstor.org/stable/40970087?seq=1\#page_scan_tab_contents

Constine, J. (2017, June 21). Snapchat launches location-sharing feature Snap Map. Retrieved from https://techcrunch.com/2017/06/21/snap-map/

Cueto, A. (2016, June 15). Mobile is \#1 for travel research and booking [infographic]. Retrieved from http://blog.operamediaworks.com/2016/06/15/mobile-is-1-for-travel-research-andbooking-infographicl

Ety Hadar. (2017). Sidekix Sightseeing, Navigation, Itinerary, Maps. [Android mobile application].

Fang, J., Zhao, Z., Wen, C., \& Wang, R. (2017). Design and performance attributes driving mobile travel application engagement. International Journal of Information Management, 37, 269-283. Retrieved from https://journals-scholarsportalinfo.ezproxy.lib.ryerson.ca/pdf/02684012/v37i0004/269_dapadmtae.xml

Google. (2017). Android 7.0 Nougat OS (Version 7). [Software]. Available from https://www.android.com/intl/en ca/versions/nougat-7-0/

Google Inc. (2017). Google Trips - Travel Planner. [Android mobile application]. Mountain View, California: Google.

Google Inc. (2017). Maps - Navigation \& Transit. [Android mobile application]. Mountain View, California: Google.

Huang, L-Y., \& Hsieh, Y-J. (2012). Consumer electronics acceptance based on innovation attributes and switching costs: the case of e-book readers. Electronic Commerce Research and Applications, 11(3), 218-228. Retrieved from https://journals-scholarsportalinfo.ezproxy.lib.ryerson.ca/details/15674223/v11i0003/218 ceaboictcoer.xml\#body$\underline{\mathrm{s} 0060}$ 
Konijn, E., Sluimer, N., \& Mitas, O. (2016). Click to Share: Patterns in Tourist Photography and Sharing. International Journal of Tourism Research, 18(6). 525-535.

Lau, G., \& McKercher, B. (2006). Understanding tourist movement patterns in a destination: A GIS approach. Tourism and Hospitality Research, 7(1). Retrieved from http://journals.sagepub.com.ezproxy.lib.ryerson.ca/doi/pdf/10.1057/palgrave.thr.6050027

Lee, H-J., \& Wilkins, H. (2015). Mass tourists and destination interaction avoidance. Journal of Vacation Marketing, 23, 3-19. Retrieved from http://journals.sagepub.com.ezproxy.lib.ryerson.ca/doi/full/10.1177/1356766715617218\# articleCitationDownloadContainer

Lonely Planet. (2017). Guides by Lonely Planet. [Android mobile application]. Oakland, California: Lonely Planet.

Lueng, R., Vu, H., Rong, J. (2017). Understanding tourists' photo sharing and visit pattern at non-first tier attractions via geotagged photos. Information Technology \& Tourism, 17(1), $55-74$.

Lynch, K. (1960). The Image of the City. Cambridge: MIT Press.

Miele, A., Quintarelli, E., Rabosio, E., \& Tanca, L. (2014). ADaPT: Automatic Data Personalization Based on Contextual Preferences. 2014 IEEE 30th International Conference on Data Engineering, 1234-1237.

Pan, S., Lee, J., Tsai, H., (2014). Travel photos: Motivations, image dimensions, and affective qualities of places. Tourism Management, 40, 59-69.

Parboteeah, D. V., Valacich, J. S., \& Wells, J. D. (2008). The Influence of Website Characteristics on a Consumer's Urge to Buy Impulsively. Information on Systems Research, 20, 60-78. Retrieved by http://pubsonline.informs.org/doi/pdf/10.1287/isre.1070.0157

Peters, T., Işık, Ö., Tona, O., \& Popovič, A. (2016). How system quality influences mobile BI use: The mediating role of engagement. International Journal of Information Management, 36(5), 773-783.

Rice, J. (2008). Urban Mappings: A Rhetoric of the Network. Rhetoric Society Quarterly, 38(2), 198-218. Retrieved from https://journals-scholarsportalinfo.ezproxy.lib.ryerson.ca/details/02773945/v38i0002/198_umarotn.xml

Rizzo, C. (2017, March 7). Let Your Facebook Friends Plan Your Next Trip. Retrieved from http://www.travelandleisure.com/travel-tips/facebook-city-guides-planner 
Spotted by Locals. (2017). Toronto guide by locals. [Android mobile application]. Amsterdam, The Netherlands: Spotted by Locals.

TripAdvisor. (2017). TripAdvisor Hotels Restaurants. [Android mobile application]. Needham, Massachusetts: TripAdvisor.

Yelp Inc. (2017). Yelp: Food, Shopping, Services. [Android mobile application]. San Francisco, California: Yelp Inc. 


\section{Glossary}

API (Application Programming Interface): a set of protocols and tools for building application software; provides building blocks to further develop a program based on an existing method of communication.

Approach-avoidance behaviour: when a goal has both positive and negatives effects or characteristics.

Compatibility: (in app context) reflects the users' perception of how the app fits travel needs and preferences; the degree of relevance the app is to the user.

Geotagging: the act of assigning geographical information to various media in the form of metadata; most commonly used for photographs to help people get specific information about where a picture was taken; based on positions and coordinates often directly taken from a GPS.

GIS (Geographic Information System): a system designed to capture, store, manipulate, analyze, manage, and present spatial or geographical data.

GPS (Global Positioning System): a radio navigation system that allows land, sea, and airborne users to determine their exact location, velocity, and time 24 hours a day anywhere in the world.

GUI (Graphical User Interface): a type of user interface that allows users to interact with electronic devices through graphical icons and visual indicators instead of text-based user interfaces, typed command labels or text navigation.

OS (Operating System): software supporting a computer's basic functions, including scheduling tasks, executing applications, and controlling peripherals.

Permissions: access details given by the users to define access rights to files on a network.

Personalization: designing and tailoring the user's needs and specifications more effectively and efficiently to heighten user engagement.

Sharing economy: an economic system in which assets or services are shared (free or at a cost) between private individuals, typically through the Internet.

User engagement: a user's response to an offering, such as a product, service, or a website; determined through interactions or user's behaviours.

UI (User Interface): the means by which the user interacts with a computer system in order to input devices and software.

Wayfinding: spatial problem solving; how people orient themselves in physical space and navigate from place to place. 